\title{
Functional Outcome with Surgical Management in Distal Tibia Fracture
}

\author{
${ }^{1}$ Dr. Lokesh Holagundi, ${ }^{2}$ Dr. Deepak S, ${ }^{3}$ Dr. Dayanad. ${ }^{4}$ Dr. Ramachandra. \\ ${ }^{1,2,3,4}$ Banglore Medical College And Research Institute.Banglore.
}

\begin{abstract}
:
Introduction: Distal Tibia fractures continue to be one of the most controversial fractures that we treat. Most of the controversy resides in the treatment techniques, as the indication for surgery is fairly clear. Plate osteosynthesis with Minimally invasive plate osteosynthesis(MIPPO) principle for fractures of the distal tibia is often associated with good healing but infection, and hardware problems.Locked intramedullary nailing is the treatment of choice for closed fractures of the tibial shaft .For proper alignment, the nail should be centrally placed in both the proximal and distal fragments, but does not fit properly into the distal fragment of the lower third of the tibia. This places additional stress on the distal locking bolts and may lead to breakage and malalignment.AIMS AND OBJECTIVES; The main aim of the study is to compare the functional recovery of the patients who had distal extraarticular fracture, AO type 43A treated with Intramedulary interlocking nail and plate osteosynthesis (Mippo). Also The aim of treating a fracture is to produce a stable construct which allows early mobilisation and weight-bearing, but with minimal complications.MATERIALS AND METHODS; This study was done in the department of orthopedics from June 2010 to January 2013 in young age above 18yr and below 60 yr. which includes 30 patients with distal tibia fractures. Patients having fracture of distal tibia at metadiaphysial area.1.Extraarticular fracture, minimum of $3 \mathrm{~cm}$ of distal fragment 2.Age above 18yrs and less than 60yr old3.Open fracturegustilo Anderson type 1 and type2SUMMARY; In this study 30 cases of distal tibia fracture were treated surgically with internal fixation with IMIL nail for 15 case and ORIF plating for 15 cases. In our study of 30 cases AO Type 43, 12 case were type A1,9 (76\%)patients operated with IMIL nail and $3(23 \%)$ patient with plating. Type A2 we had 12 cases out of which 5 patients(41.6\%) treated with nail and 7 patient $(58.3 \%)$ treated with plate.TypeA3 we had 6 cases.one case $16.6 \%$ treated with nail and 5 cases $83.3 \%$ with plate. We faced more malalignment(11.11\%),delayed union(16.6\%),non union(5.5\%),secondary procedure $22.2 \%)$ done for the complication was more with nail where as with plate group we never had significant malalignment.Had one delayed union(32weeks) for which no secondary surgery done,One superficial skin necrosis of surgical site.CONCLUSION; In study of distal tibia fractureOTA $4 O 43$ Type A, we compared with both nail and plate surgery. We conclude that segmental alignment is difficult with nail due ankle joint is near ,more distal the fragment difficult to treat with nail. Because of more complication associated with nail than plate.We conclude plating in distal tibia fracture AO 43 TypeA is safe and provide better alignment than nail.
\end{abstract}

\section{Introduction}

The management of Distal tibia fractures has always held a particular interest for orthopaedic surgeons. Not only are these fractures relatively common, but they are often difficult to treat. The subcutaneous location of the anteromedial surface of the tibia means that severe bone and soft tissue injury is not infrequent, and there is a high incidence of open fractures compared with other long bones. Until relatively recently, surgeons had to rely on nonoperative management, and the incidences of nonunion, malunion, and joint stiffness were high.Tibial diaphyseal fractures commonly affect young males, and a severe fracture complicated by nonunion or infection often results in employment loss or other social and economic problems. These complications also place a considerable strain on the health services of all countries.Surgical stabilization of fractures and early mobilization of the patient provides best clinical outcome. Although treatment planning for fracture should be considered individually to achieve the optimal results. The effect of decision must be considered in the light of overall injury status and general condition of the patient.Distal Tibia fractures continue to be one of the most controversial fractures that we treat. Most of the controversy resides in the treatment techniques regarding the choice of implants, as the indication for surgery is fairly clear.

Some surgeons treat the fracture based on fracture pattern and level of the fracture, mostly on external fixation if soft tissue injury is found, whereas others use predominately plate fixation and some prefer nailing techniques. These areas of controversy would seem to be an excellent target for prospective clinical research. Surgeons should be warned, however, that there are reasons that answering these questions is exceedingly difficult. Fracture patterns are complex, diverse, and technically demanding and do not lend themselves well to random allocation. In addition, the factors that lead to good versus poor outcomes often depend on treatment 
techniques than other factors, which can be controlled. For these reasons, new treatment techniques may need to continue to be evaluated in case series and cohort studies.

In Plate osteosynthesis for fractures of the distal tibia is often associated with delayed healing, infection, and hardware problems ${ }^{29}$. with MIPPO method rate of delayed union and infection rate is come down.Locked intramedullary nailing is the treatment of choice for closed fractures of the tibial shaft ${ }^{31,32}$. For proper alignment, the nail should be centrally placed in both the proximal and distal fragments ${ }^{4,29}$, but most of the time does not fit properly into the distal fragment of the lower third of the tibia which leads complications. This places additional stress on the distal locking bolts that may lead to breakage and malalignment.Intramedullary nailing of more distal fractures is possible, but the ability to maintain a mechanically stable reduction becomes more difficult ${ }^{10}$. We assessed the results of intramedullary nailing and plate osteosynthesis for fractures of the distal tibia and fibula.

\section{Aims And Objectives}

The main aim of the study is to compare the functional recovery of the patients who had distal extra articular fracture AO type 43A treated with Intramedullary interlocking nail and plate osteosynthesis. Also The aim of treating a fracture is to produce a stable construct which allows early mobilization and weight-bearing, but with minimal complications.some study shown that patients with a distal metaphyseal fracture of the tibia would recover better after closed IMN than after open reduction and internal fixation with plating ${ }^{3.5}$. We also compared the operating time, imaging time, rate of wound problems, the time to union of the fracture and mobility after one year.

And also to assess incidence of distal tibia fracture, To study the better modality of surgical treatment various factors affecting the functional outcome, study complication associated with each surgical treatment.

\section{Classification}

Classification systems have been devised to describe more accurately the wide range of distal tibial fractures. The AO/OTA classification system provides a comprehensive description of distal tibial fractures. AO\OTA 43Type A fractures are extraarticular distal tibial fractures, which are subdivided into groups A, B, and $\mathrm{C}$, based on the amount of metaphyseal comminution and intra articular extension.In type $\mathrm{A}$ again subdivided into ,43A1 simple extraarticular fracture. 43A2 metaphysial wedge,43A3 metaphysial communation.
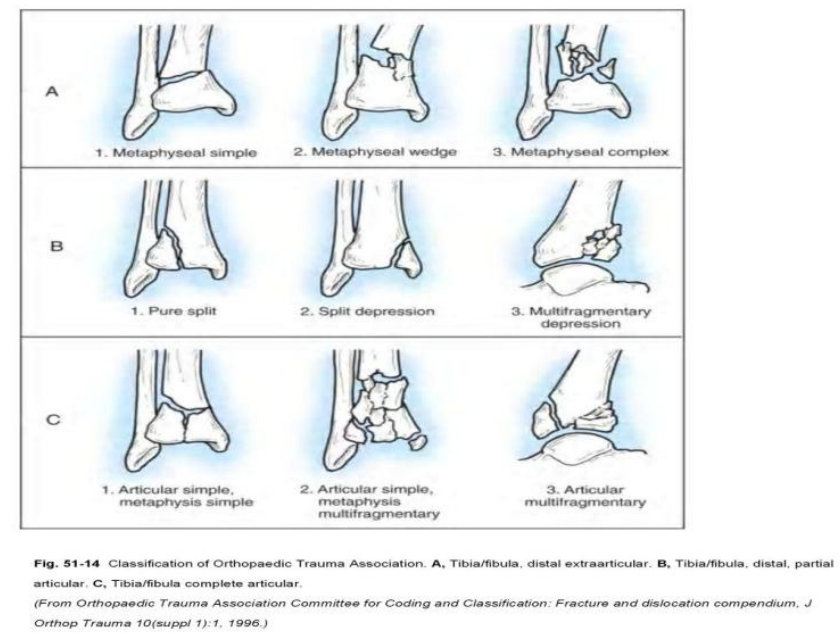

Another classification by Robinson ${ }^{1}$ et al

Type I simple exra articular,transverse or oblique

Type IIa -extra articular

IIb - associated with medial malleoli fracture

IIc - associated with posterior malleoli 


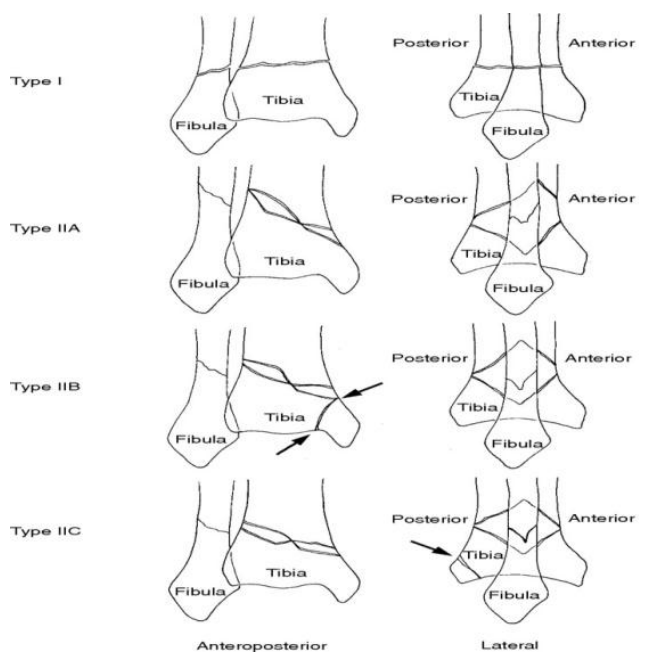

IV. Materials And Methods

This study was done in the department of orthopedics at Banglore medical college from June 2010 to January 2013 in young age above 18yr and below 60 yr. which includes 30 patients with distal tibia fractures. The Patients with Distal tibia fracture who came to our hospital Grouped into Group A and Group B.For each Group patients are Randomly allocated with help of computer. Group A patients are treated with Intramedullary interlocking nail,Group B Patients are treated with open reduction and internal fixation with Plating.Preoperatively History taken regarding Mode of injury,Time of injury ,Personal history,Treatment history are documented.Work up done for surgical management.Consent was taken from all the patient.

This prospective Randomized study was analyzed. This study was done after approval from the ethical Committee of our hospital.

Inclusion Criteria ;Patients having fracture of distal tibia at metadiaphysis.

1.Extraarticular fracture, minimum of $3 \mathrm{~cm}$ of distal fragment

2.Age above 18yrs and less than 60yrold

3.Patients who are medically fit for surgery

\section{ExclusionCriteria}

1.Pathological fracture.

2.All open fracture

3.Patients who are medically Unfit and not willing for surgery.

Postoperatively, patients were kept non-weight-bearing. Active and passive movements were encouraged. At 6 weekly the progress of healing was assessed using radiographs and weight bearing was initiated. Malalignment (angulations of $>5^{\circ}$ in any plane)was assessed by comparison with the normal leg. Patients were followed up at 6,12,18and 24 week and then every 3 months during the first year and 6 monthly thereafter. Assessment of the patient with Functional recovery was done with American orthopaedic foot and ankle surgery $(\mathrm{AOFAS})^{27}$ minimum 5 month after injury.

\section{Observations}

A comparative study done for distal $3^{\text {rd }}$ tibia fractureTreated with intramedullary nailingGroup A and Plating Group B in Orthopaedic department between date of June 2010 to January2013..follow up done minimum 5months. following observation made in the study.

1) Age distribution; In our study majority of the Patients are from age group 18-29 years (43.3\%). The youngest patient was 18 years old and oldest was 54 years. Out of 13 cases of second decade, 8(26.6\%) cases Randomized into Group A,remaining 5(16.6\%) cases into Group B.There was 10 cases from $3^{\text {rd }}$ decade, 4(13.3\%)cases into Group A and 6(20\%)cases into GroupB,3cases from $4^{\text {th }}$ decade $1(3.3 \%)$ case to GroupA and $2(6.6 \%)$ case to Group B ,4 cases from $5^{\text {th }}$ decade, 2(6.6\%)cases into GroupA and 2 cases into GroupB Randomly divided.

2.Sex distribution; Majority of the patients were males $80.6 \%$ (24) and $19.3 \%$ (6) patients were females. In our study there was $24(80 \%)$ Male and 6(20\%) female patients present.In GroupA 11(36.6\%)males and 4(13.3\%) Female patients undergone surgery.In Group B 13(43.3\%)male and 2(6.6\%)Female undergone surgery

3) Side distribution : In our study 23(76.6\%) patients had right side injury out of which 13(43.3\%) patient undergone treatment under GroupA and 10(33.3\%) patients under GroupB.7(23.3\%)patients had left side out of which $2(6.6 \%)$ patients taken treatment under GroupA and 5(16.6\%) patients under GroupB 
4)Mode of injury; In our study we had 22 patients who sustained Road Traffic Accident(73.3\%).4(13.3.\%)patients direct injury,4(13.3\%)patients had fall from height.

5)Type of fracture;In our study 12 patients had AO 43A1,9patients undergone treatment under GroupA and 3 patients under Group B. 12 Patients had AO 43A2 type, in which 5 patient undergone treatment under Group A and 7 patient under Group B.6 patients had AO43A3 type ,in which 1 patient undergone treatment under GroupA and 5 patients under GroupB.

6)Associated injuries ; our study had 4 head injury, 2 clavicle and 2 medeal malleoli fracture.

7)Complication;In our present study we had 3 cases of Delayed union and one case Gone into Non union in Group A.Where in group B had one case superficial infection and Delayed wound healing.

8)Secondary procedure; 4 out of 15 case had require secondary procedure in Nailing group and 1 case in Plating group.

\begin{tabular}{|l|l|l|l|l|}
\hline surgery & No of cases & percentage \\
\hline \multirow{2}{*}{ Nail } & 4 & Dynamisation & 2 & $26.6 \%$ \\
\cline { 3 - 4 } & & Bone grafting & 1 \\
\cline { 3 - 4 } & $\begin{array}{l}\text { Exchange nail and } \\
\text { bone graft }\end{array}$ & 1 \\
\hline Plate & 1 & $6.6 \%$ \\
\hline
\end{tabular}

9)Intra and post operative variable:In given below table we compared intra operative and post operative variables. The mean operating time in nail i,e GroupA was 123 minutes, where in GroupB 107 minutes, mean radiating time was 3 minutes in groupA and 2.2minutes in groupB.Mean union time in groupA Is 21 weeks and 20 weeks in groupB.one patient had Wound problem in groupB.3patients complained knee pain from groupA. In groupA 3 patients had delayed unionand one patient had non union. 10days was the mean hospital stay in both group. 2 patient had malalignment from groupA.

\begin{tabular}{|l|l|l|}
\hline & Group A & GroupB \\
\hline Mean operating time(min) & 123 & 107 \\
\hline Mean radiation time(min) & 3 & 2.2 \\
\hline Meantime of union(wk) & 21 & 20 \\
\hline Wound problem & 0 & 1 \\
\hline Knee Pain & 3 & 0 \\
\hline Delayed union & 3 & 0 \\
\hline Malalignment & 2 & 0 \\
\hline Mean Hospital stay (day) & 10 & 10 \\
\hline Non union & 1 & 0 \\
\hline Secondary procedure & $26.6 \%$ & $6.6 \%$ \\
\hline
\end{tabular}

10.Functional outcome; The functional outcome was assessed by American ankle and foot score.In our study 8(53.3\%)patients had exellent ,4(26.6\%) patients had good,1(6.6\%) patient had fair and 2(13.3\%)patients had poor functional outcome from groupA.In groupB ,8(53.3\%) patients had excellent,6(40\%)patients had good and $1(6.6 \%)$ patient had fair outcome

\section{Discussion}

The management of Distal tibia fractures has always held a particular interest for orthopaedic surgeons. Not only these fractures relatively common, but they are often difficult to treat. The subcutaneous location of the anteromedial surface of the tibia means that severe bone and soft tissue injury is not infrequent, and there is a high incidence of open fractures compared with other long bones. Until relatively recently, surgeons had to rely on nonoperative management, and the incidences of nonunion, malunion, and joint stiffness were high.Due to increase in number of vehicle and increase high velocity motor vehicle accidents, prevalence of fracture is increased.

In prospective Randomized study of distal tibia fracture treated with closed reduction and internal fixation with intramedullary nail GroupA compared with open reduction and fixation with plating GroupB. The study done in $\mathrm{kg}$ hospital and post graduation institute between june 2010 to January2012.In our study we compared 15 cases in each group .we compared our study with other studies which are published before in journal.

Age Discussion; Mean age of Krishna ${ }^{19}$ et al study was $35 \mathrm{yr}$,Kasper w jassen ${ }^{15}$ et al study mean age was 43.3 year,Jiayuan hong ${ }^{26}$ et al study had mean age of 38 years.J J.Guo ${ }^{20}$ et al study had mean age of 54year in nailing group and 51 year in plating group. In our study mean age was 39year in both group.

Sex Discussion; Sex distribution with other study was compared krishna ${ }^{19}$ et al study had $60 \%$ male patients and $40 \%$ female patients.kasper $w$ janssen ${ }^{15}$ et al study nailing group had $25 \%$ male, $25 \%$ female and in plating group 
had $25 \%$ male and $25 \%$ female.J J Guo ${ }^{20}$ et al had $40 \%$ female and $59 \%$ male in nailing group , $41 \%$ female and $59 \%$ male in plating group.

Side Discussion; Side distribution in many study not quoted $\mathrm{J} \mathrm{J} \mathrm{Guo}{ }^{20}$ et al had $54 \%$ of left side had taken treatment with nailing and51\% of left side taken treatment with plating. In our study 23 case $(76.6 \%)$ had on right side in which $43 \%$ treated with nailing groupA,33\%treated under plating groupB. 7 cases $(23.3 \%)$ had on left side, 2 case treated with nail and 5 cases treated with plate group.

Associated Injury Discussion; We had 13\%(4case)Head injury but who are managed conservatively and all of these underwent surgery in GroupA after randomized,6.6\%(2case)had clavicle fracture and these are treated one on each group.6.6\% (2case)had medial malleoli fracture and both are treated under groupA.

Type Of Fracture; We followed OTA\AO classification as other Author also did and compared the prevalence of type of fracture and treatment they undergone.

\begin{tabular}{|l|l|l|l|}
\hline 43A1 & KASPER $^{15}$ & J.J Guo $^{20}$ & Our study \\
\hline GroupA & $58 \%$ & $29 \%$ & $60 \%$ \\
\hline GroupB & $33 \%$ & $31 \%$ & $20 \%$ \\
\hline 43A2 & \multicolumn{3}{|l|}{} \\
\hline GroupA & $16 \%$ & $36 \%$ & $33 \%$ \\
\hline GroupB & $50 \%$ & $29 \%$ & $46 \%$ \\
\hline 43A3 & \multicolumn{2}{|l|}{} \\
\hline GroupA & $25 \%$ & $34 \%$ & $6 \%$ \\
\hline GroupB & $16 \%$ & $39 \%$ & $33 \%$ \\
\hline
\end{tabular}

Kasper w janssen ${ }^{15}$ et al study treated $58 \%$ of the typeA1 fracture with nailing $38 \%$ cases with plate.J J $\mathrm{Guo}^{20}$ et al study treated $29 \%$ of the type A1 fracture with nailing and $31 \%$ treated with plate.our study $60 \%$ of the cases treated with nailing and $20 \%$ with plate.Type A2 fracture kasper ${ }^{15}$ et al study treats $16 \%$ with nailing,50\% with plating, $\mathrm{J} \mathrm{J}$ Guo ${ }^{20} \mathrm{et}$ al study treats $36 \%$ nailing and $29 \%$ plating,our study $33 \%$ of the patients treated with nailing group and $46 \%$ with plating group.Type A3 fracture, kasper ${ }^{15}$ et al study had $25 \%$ cases treated with group A and $16 \%$ with groupB.J J Guo ${ }^{20}$ et al had treated $34 \%$ cases with groupA and $39 \%$ with groupB.our study had $6 \%$ case treated with groupA and $33 \%$ cases with groupB.

\section{Discussion About Complication}

Im $\mathrm{Gi}^{10}$ et al in his study, ORIF can restore alignment better than IMnailing. They treated 64 consecutive distal tibia fractures with ORIF or IM nailing. They found an average angulations of $0.9^{\circ}$ after plating versus $2.8^{\circ}$ after IM nailing $(\mathrm{p}=0.01) \cdot \mathrm{kasper}^{15}$ et al had malalignment in 2 of the 12 patients $(17 \%)$ treated with plate and in 6 of the 12 patients $(50 \%)$ treatedwith IM nailing $(\mathrm{p}=0.1)$. Vallier ${ }^{17}$ et al shown that angular malalignment is more with nail ,varus of more than $5^{\circ}$ in $29 \%$ and $5.4 \%$ with plating.Our studyin the distal third of the tibia fracture, malignment in more than $5^{\circ}$ varus found in $2(13 \%)$ patients treated with nailing group none of the plating group had malalignment more than $5^{0}$ varus or valgus.

Vallier ${ }^{17}$ et al had $12 \%$ delayed and non union with nailing group. $2.5 \%$ non union with plating group.Kasper ${ }^{15} \mathrm{et}$ al in his study found $25 \%$ delayed union with nailing and $16.5 \%$ plating.Our study shows $16.6 \%$ delayed union with nailing and $6.6 \%$ with plate. One case6.6\% non union with nail.

Kasper ${ }^{15}$ et al studyMean time of radiographic union was 19 weeks with plate group and 21 week with nail group with.J Jguo ${ }^{20}$ et al study 17.7 weeks for mean radiographic union with nailing and 17.6 weeks for plate group.Vallier ${ }^{17}$ et al shown his study that mean union time is 19 weeks for both plate and nail group.Our study had mean radiographic union with plate is 20 weeks and 21 weeks with nailing group.

Hernigou P, Cohen $\mathrm{D}^{13}$. et al in 2000 , The intra-articular structures particularly at risk of damage during tibial nailing are the medial meniscus, the lateraltibial plateau and the ligamentum transversum.A probableexplanation is that the pain was not only caused by thearticular penetration but also by the presence of the nail,i.e., by the bending strain exerted by the proximal part ofthe nail on the bone. Since unrecognized articular penetration occurs with the use of nails of large diameter in smallpatients, the bending strain at the upper end may alsoincrease in such individuals.

$\mathrm{J} \mathrm{J} \mathrm{Guo}{ }^{20}$ et al had $13 \%$ of the patient who treated with nailing group had knee pain especially on bending. In our study three(20\%) patients had anterior knee pain without hindering knee range of motion,especially when kneeling they had more pain.so it made them to remove the hard ware.

Kasper $^{1}$ et al had Secondary procedure with nailing is more $25 \%$ compare to plate .In our study $26 \%$ secondary procedure done for three delayed union $20 \%$ and one non union $(6.6 \%)$ in nail group, for which two patients underwent dynamisation and one patient bone grafting with exchange nailing,finally all cases united.one case non union treated with exchange nail and bone graft. One case6.6\% from plating group had delayed wound healing and necrosis for which wound debridment and secondary suturing did same patient had delayed union for which no secondary surgery done. 


\section{Intra And Post Operative Variable}

$\mathrm{J} \mathrm{J} \mathrm{guo}{ }^{20}$ et al ,compared intra and post operative variable,Mean operating time,Radiation time ,mean time to union patients with other complication we compared.

\begin{tabular}{|c|c|c|c|c|}
\hline \multicolumn{3}{|c|}{ J J Guo et $\mathrm{al}^{20}$} & \multicolumn{2}{|l|}{ Our study } \\
\hline & GroupA & GroupB & GroupA & GroupB \\
\hline $\begin{array}{ll}\text { Mean } & \text { operating } \\
\text { time }(\min )\end{array}$ & 81.23 & 97.9 & 123 & 107 \\
\hline $\begin{array}{ll}\text { Mean } & \text { radiation } \\
\text { time }(\min ) & \\
\end{array}$ & 21.2 & 3 & 3 & 2.2 \\
\hline $\begin{array}{l}\text { Mean time to } \\
\text { union(wks) }\end{array}$ & 17.7 & 17.6 & 21 & 20 \\
\hline AOFAS Mean score & 86.1 & 83.9 & 85.3 & 84.5 \\
\hline Wound problem $(\%)$ & $6.8 \%$ & $14.6 \%$ & 0 & 6.6 \\
\hline
\end{tabular}

\section{Conclusion}

Our aim of study is to prove Concept of management of distal tibia fracture management with early union,weight bearing with less complications with either of the surgical methods of fixation. Management of these fracture even controversial but effectively can be treated with both Nail and plate.

Distal tibia is more subcutaneously placed hence soft tissue injury along with fracture should be consider carefully before planing for plate fixation.

In our comparative randomized study ,even though functional outcome with both the group was comparable.But considering the complication,requirement of secondary procedure with nailing was more.

Complication such as Delayed union,non union and malalignment was more with nailing.

One case which went into non union was typA3,probably due to communution and dificult alignment peroperatively. 2 cases which wentfor delayed union treated with nail are oneA2 and one caseA1.

Malalignment with nailing was more probably due ankle joint is near and difficult reduction.

Mean functional out come and mean union time was comparable.In nailing mean union time was 21 week and plating 20 week.functional outcome measure with AOFAS mean score was not significantly different.

For fracture type 43A both Intramedullary interlocking nail and open reduction and plate fixation are good and comparable,but comparing to secondary complication plating is the better option.

\section{References}

[1]. Robinson CM,Mclaughlan GJ,Mclean IP,Court-Broun CM. Distal metaphyseal fracture of tibia with minimal involvement of the ankle; classification and treatment by locked intramedullary nail.J bone joint $\operatorname{surg}($ br).1995nov:77(b):781-87

[2]. Bonnevialle P,Savorit L,Combes JM,Rongieres M,Bellumore Y,Mansat M.et al.The value of intramedullary locking nailing in distal tibia fracture.Rev Chir Orthop ReparatriceApparMot[Internet].1996;82(5):428-36.Article in French. available from:http://www.ncbi.nlm.nih.gov/m/pubmeb/8991166.

[3]. Hernigou P,Cohen D.et al. Proximal entry for intramedullary nailing of tibia, the risk of unrecognized articular damage. Jbone joint surg.2000jan;82B(1):33-41.

[4]. Tyllianakis M,Megas P,Giannikas D,Lambiris.et al.The result of non pilon fracture of the distal part of tibia treated with interlocking intramedullary nailing.Jorthop[Internet].2000aug;23(8):805-08.available from.http://www.ncbi.nlm.nih. gov/pubmed.

[5]. Gorczyca JT, Mckale J,Pugh K,Pienkowski D. et al.The modified tibial nail for treating distal tibia fracture.J orthop and trauma[Internet].2002jan;16(1):18-22.available from:http://www.ncbi.nlm.nih.gov/pubmed/11782627.

[6]. Borg T, Larsons,Lindsjou. Percutaneous plate of distal tibia fractures;preliminary result in 21patients. J injury[Internet].2004jun;35(6):608-14.available from:http:// www.injuryjournal.com/article/S00201383(03)00329-2.

[7]. Yang SW,Tzeng HM,Chou YJ,Teng HP,Liu HH,Wong.et al.Treatment of distal tibial metaphyseal fractures :plating versus shortened intramedullary nailing.J Injury[Internet].2006jun[cited 2006jan17];37(6):531-35.available from:http://ww w.ncbi.nlm.nih.gov/pubmed/16413025

[8]. Francois,Vandeputte,Frank, Guy Nelen.Percutaneous plate fixation of fracture of distal tibia.J actabelgica[Internet].2004jan;70(2):148-54.available from:http://www .actaorthopaedica.be/.

[9]. Nork E,Schwartz K,Agel,Holt K,Schick L,Winquist A.Intramedullary nailing of distal metaphyseal tibia fractures.J bone joint $\operatorname{surg(am)[Internet].~2005jun01;87(6):1213-21.available~}$ from:http://www.jbjs.org/article.aspx.articleid27040. 
[10]. Imgi,Taesk.Distal metaphyseal fracture of tibia;a prospective randamised trial of closed reduction and intramedullary nail versus open reduction and plate and screw fixation.J trauma[Internet].2005nov;59(5):1219-23.available

from:http://www.ncbi,nlm.nih.gov/pmc/article/pmid:16385303.

[11]. Bedi A,Le TT,Karunakar MA.Surgical treatment of non-articular distal tibia fractures.J Am AcadOrthopSurg[Internet].2006jul;14(7):406-14.available http://www.ncbi.nlm.nih.gov/pubmed.

[12]. Boris A Zelle,MohitBhandari,Michael Espiritu,Kenneth J Koval,Micheal Zlowodzki et al.Treatment of distal tibia fracture without articular involement-a systemic review of 1125 cases.J Orthop trauma[Internet].2006jan;20(1):76-9.avalable from:http://www.ncbi.nlm.nih.gov/pubmed/16424818.

[13]. Hazarika S,Chakravarthy J,Cooper.et al.Minimally invasive locking plate osteosynthesis for fractures of the distal tibia results in 20 patients.J Injury.2006sep;37(9):877-87.

[14]. Mohammed,Saravanan,Zammit,Richard King. Et al.The intramedullary tibial nailing in distal third tibia fracture,distal locking screw and fracture non union.J Int orthop[Internet].2008Aug[cited2007 apr];32(4):547-49. Available from:http://ww w.ncbi.nlm.nih.gov/pmc/articles/pmc2532262.

[15]. Janssen W,Biert,Kampen.Treatment of distal tibia fracture;plate versus nail,retrospective outcome analysis of matched pairs of patients.J Int orthop[Internet].2007october[cited2006dec12];31(5):709available from:http:// www.ncbi.nlm.nih.gov/pmc/article/pmc2266640.

[16]. Strauss EJ,Alfonso D,Kummer FJ,Egol KA,Tejwani NC.et al.The effect of fibular fracture fixation on distal tibia fracture.J Orthop trauma[Internet].2007mar: 21(3):172-73.available from:http://www.ncbi.nlm.nih.gov/pubmed.

[17]. Vallier HA,Bedi.Radiographic and clinical comparison of distal tibia fracture $(4-11 \mathrm{~cm}$ from plofond)nailing versus platng.J Orthop trauma [Internet].2008may;22(5):307-11.available from:http://journals.lww.com/jorthotrauma/Absract/ 2008.

[18]. Mustaq,Shahid,Asif,Masqood.Distal tibia fracture fixation with LCP using MIPO.EuropeanJ Trauma and Emergency

from:http://www.link.springer.com/article/10

[19]. Krishna A,Peshin C,Singh D.Intramedullary nailing and plate osteosynthesis for fracture distal metaphyseal tibia and fibula.J Orthop Surg(hongkong) [Internet].2009dec;17(3):317-20.available from:http://www.ncbi.nlm.nih.gov/ pubmed/20065372.

[20]. Guo J,Tang N,Yang H L,Tangt.A prospective randamized trial comparing closed intramedullary nailing with percutaneous plating in treatment of distal metaphyseal fractures of tibia.J bone joint $\operatorname{surg}(\mathrm{BR}) .2010 \mathrm{jul} ; 92 \mathrm{~B}(7)$ :984-88.

[21]. Dorga et al.fracture of lower limb.In:s,terry canale,James H Beat editors.Campbell`s Operative Orthopaedics. $11^{\text {th }}$ Ed Vol 3.Mosby publication.3123-25.

[22]. Ehlinger M,Adam P,Gabrion A,Jeunet L,Dujardin F,Asencio G,Sofco T.et al.Distal quarter leg fracture fixation;intramedullary nailing alone option.J orthop trauma.2010oct;96(6):674-82.

[23]. Gupta RK, Rohilla RK,Sangwan K,Singh V,Walia S.et al.Locking plate fixation in distal metaphyseal tibia fracture.J Int orthop.2010dec;34(8):1285-90.

[24]. Collinge,Protzman.Outcome of minimally invasive plate osteosynthesis for metaphyseal fracture disatl tibia.J Orthop trauma[Internet].2010jan;24(1):24-29. available from:http://www.scribd.com/.

[25]. Lucas,Brennen L.Value of intramedullary locking nail in distal tibia fracture.J Int Orthop[Internet].2011.avalable from:http://www.ncbi.nlm.nih.gov.

[26]. Hong J,Zeng R,Lin D,Linxinguo,Kang L,Ding Z,Xiao J. et al.The postereomedial anatomical plate for treatment of distal tibia fracture with anterior soft tissue injury.J Orthop.2011jun;34(6):161-64.

[27]. Kitaokahb,Alexanderij.Clinical rating system of the ankle,hindfoot,midfoot, hallux and lesser toes.J Foot ankle Int[Internet].1994jul;15(7):349-53.available from:http://www.ncbi.nlm.nih.gov/pubmed.

[28]. Ruedi , Murphy WM.et al.Book of AO principal of fracture management.AO publication,2005 edition:541.

[29]. Tanna DD.et al .Interlocking nailing .In;Book of elements of fracture fixation. $2^{\text {nd }}$ ed.New Delhi;Jaypee Publishers:2004.

[30]. Whittle AP,Wood GW. In: Campbell's operative orthopaedics.10 ${ }^{\text {th }}$ ed.Canale ST.et al.St Louis:Mosby;2003:2757-61.

[31]. Schmidt AH,Finkemeier CG,Tornetta P.et al.Treatment of closed tibial fractures. $3^{\text {rd }}$ Instr Course Lect[Internet].2003;52:607-22.available from:http://book s.google.co.in. 
Illusration Of Cases;

Case 1;
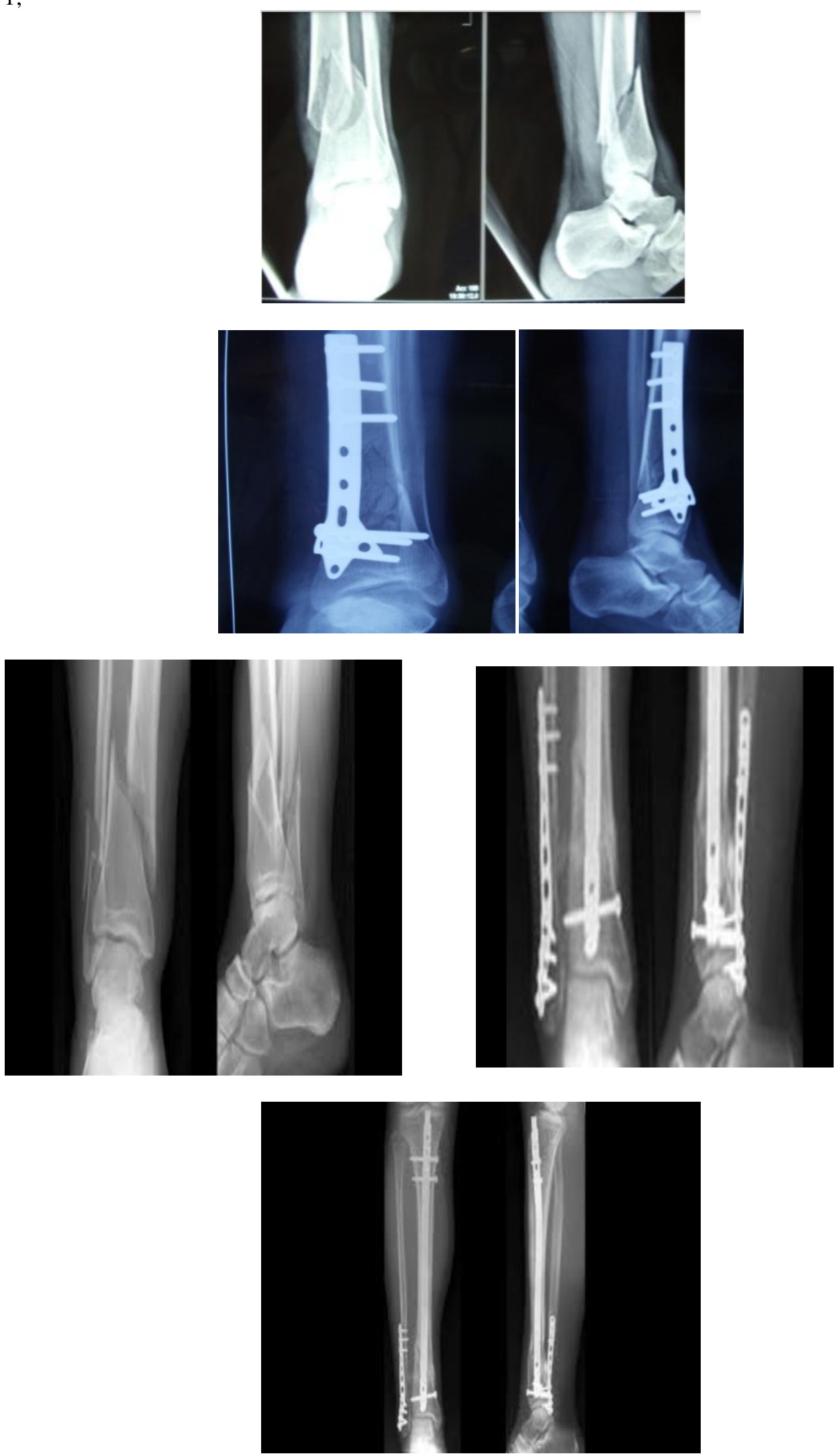